\title{
RANCANG BANGUN PROTOTIPE AUTOMATIC SLUICE PADA PINTU AIRBERBASIS INTERNET OF THINGS
}

\author{
Andy Prasetyo ${ }^{1}$, Wasum ${ }^{2}$, Muhammad Priyono Tri S. ${ }^{3}$ \\ Prodi Teknik Informatika, Universitas Kanjuruhan Malang ${ }^{1,2,3}$ \\ Email: andypras0404@gmail.com
}

\begin{abstract}
Abstrak. Khususnya untuk di jalan, adanya sistem transportasi yang memadai dapat mejadi peranan penting dalam memberikan kebutuhan yang ada. Tinggi intensitas curah hujan menyebabkan beberapa daerah sering dilanda bencana banjir pada musim hujan. Dengan memperhatikan hal tersebut, maka perlu pembuatan "Rancang Bangun Prototipe Automatic Sluice Pada Pintu Air Berbasis Internet of Things" yang dapat membuka dan menutup secara otomatis dan memonitoring ketinggian air melalui IoT. Hasil pengujian pada Rancang bangun prototipe automatic sluice pada pintu air berbasis Internet of Things, kondisi komponen lainnya dalam keadaan baik,pembacaan data sensor secara akurat antara permukaan dengan batas ketinggian air, dan untuk pintu air otomatis berjalan sesuai dengan pembacaan sensor dan untuk monitoring alat pengambilan data berjalan dengan baik dan untuk pengukuran ketinggian dan lamp indikator pada IoT sesuai dengan hasil dari pengujian.
\end{abstract}

Kata Kunci: Jalan, banjir, prototipe, pintu air, IoT

\section{PENDAHULUAN}

Prasarana yang melampaui volume lalu lintas yang tinggi akan menyebabkan terjadinya penurunan kualitas jalan sebagaimana indikatornya dapat diketahui dari kondisi permukaan jalan. setiap pergerakan, baik pergerakan manusia maupun barang khususnya untuk di darat, selalu menggunakan sistem transportasi yang ada, sehingga peranan jalan menjadi sangat penting dalam memfasilitasi kebutuhan pada pergerakan yang ada. Tingginya intensitas curah hujan menyebabkan beberapa daerah sering dilanda bencana banjir pada musim hujan. banjir yang terjadi akibat intensitas curah hujan yang tinggi di mana terjadi kelebihan air yang tidak tertampung pada suatu wilayah. Kondisi tersebut berdampak pada timbulnya genangan di wilayah tersebut yang dapat merugikan masyarakat sekitarnya.

Berdasarkan permasalahan yang ada, peneliti membuat sistem buka tutup pintu air secara otomatis apabila ketinggian air melebihi batas yang telah ditentukan oleh sistem maka pintu tersebut akan terbuka dan tertutup secara otomatis. Sistem juga dapat memonitoring ketinggian air melalui platform IoT yang dibuat. Sehingga peneliti membuat rancang bangun prototipe pintu air otomatis berbasis IoT. Adanya penerapan sistem ini dapat memberikan solusi terhadap pemecahan masalah setelah banjir yaitu untuk mengurangi adanya genangan atau meluapnya air yang diakibatkan derasnya air hujan.

Permasalahan diatas maka yang akan dibahas adalah bagaimana membuat rancang bangun, monitoring, dan pengujian prototipe pada Pintu Air berbasis Internet of Things. Untuk membuat rancang bangun, monitoring, pengujian dan analisa terhadap prototipe pintu air berbasis Internet of Things adalah tujuan dari penelitian ini.

\section{METODE PENELITIAN}

\section{Analisis Perancangan}

Perancangan sebuah sistem memerlukan fasilitas dan bahan untuk pembuatan sistem, diperlukan beberapa fasilitas untuk pendukung kinerja pembuatan alat yang akan dijalankan. 
Fasilitas dan bahan yang dibutuhkan sebagai pendukung pembuatan alat agar berjalan dengan baik adalah perangkat keras dan perangkat lunak.

a. Analisis Kebutuhan Perangkat Keras.

Perangkat keras diperlukan untuk memenuhi kebutuhan fisik suatu alat agar dapat berjalan sesuai tujuan. Adapun komponen perangkat keras yang dibutuhkan pembuatan alat Pintu air otomatis berbasis Internet of Things ini adalah sebagai berikut :
1. Arduino Uno DIP
2. Modul Ethernet Shield
3. Sensor Ultrasonik HC-SR04
4. Mekanik DVD
5. Driver L293D
6. LCD $16 \times 2+\mathrm{I} 2 \mathrm{C}$
7. Adaptor $2 \mathrm{~A}$.

b. Analisis Kebutuhan Perangkat Lunak.

Perangkat lunak adalah perangkat yang tidak bisa disentuh (abstrak). Perangkat lunak berguna untuk memperdayakan perangkat keras. Adapun komponen perangkat lunak yang dibutuhkan pembuatan alat pintu air otomatis berbasis Internet of Things ini menggunakan Arduino IDE dan Thingspeak.

c. Desain Perancangan.

Tahap desain meliputi kriteria desain sistem, desain perangkat keras dan flowchart.

d. Desain Sistem.

Dalam pembuatan alat ini menggunakan sensor ultrasonik yang berfungsi jika air melebihi batas ketinggian yang telah di tentukan maka sensor ultrasonik ini terhubung dengan Mikrokontroller. Setelah air terdeteksi sensor yang berarti air tersebut melebihi batas ketinggian yang ditentukan maka pintu otomatis akan terbuka. Dan informasi batas ketinggian air akan dikirimkan melalui Ethernet Shield sebagai penghubung jaringan internet ke IoT. Mikrokontroller juga memberikan perintah untuk menggerakan Mekanik DVD yang membuka dan menutup pintu secara otomatis.

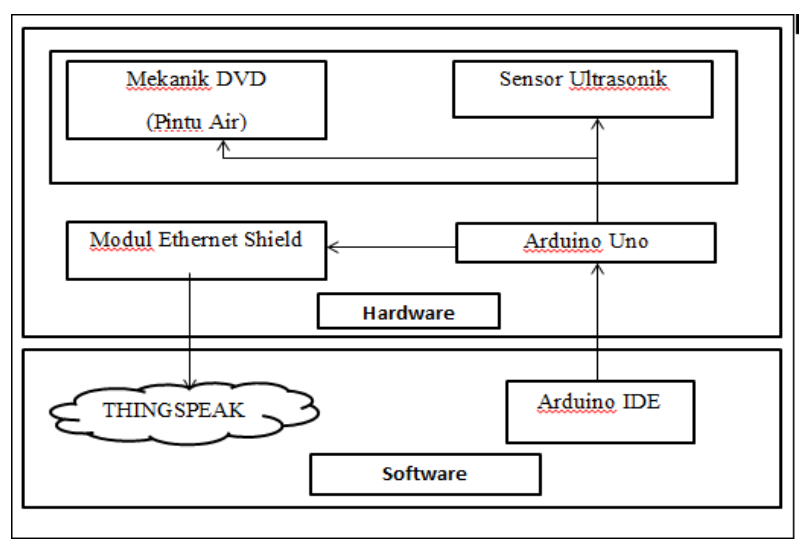

Gambar 1. Blok Diagram 
e. Desain Perangkat Keras.

Komponen utama yang berupa fisik dan nyata. Perangkat keras sangat dibutuhkan untuk menunjang berjalannya sistem secara fisik. Sebelum pembuatan bentuk fisiknya maka peneliti merancang desain perangkat keras. Berikut adalah desain perangkat keras sketsa dan elektrikal.

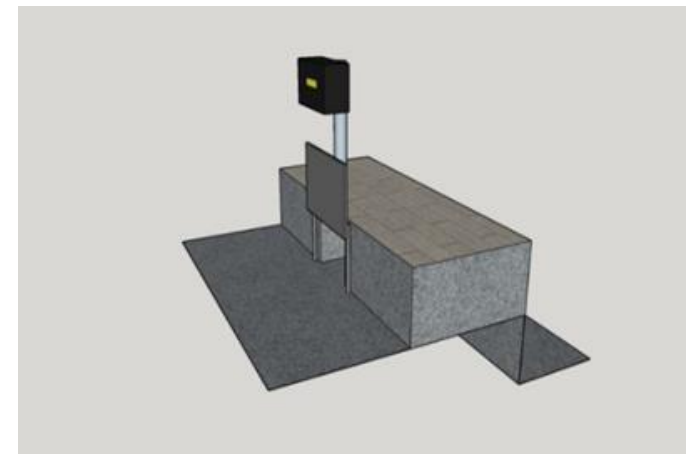

Ganbar 2. Desain Sketsa Seluruh Bagian

f. Rangkaian Elektrikal

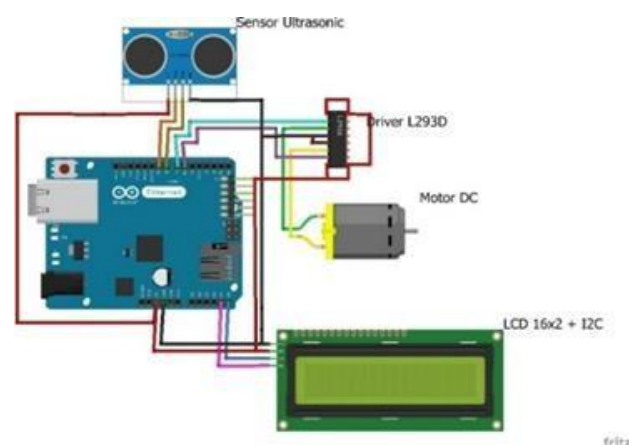

Gambar 3. Rangkaian Elektrikal Keseluruhan

\section{Flowchart Hardware dan Software}

Sebelum melakukan implementasi perangkat lunak dilakukan pembuatan bentuk flowchart agar mudah dalam membuat perangkat lunak dalam alat ini. Berikut adalah flowchart hardware dan software. 
a. Flowchart Hardware

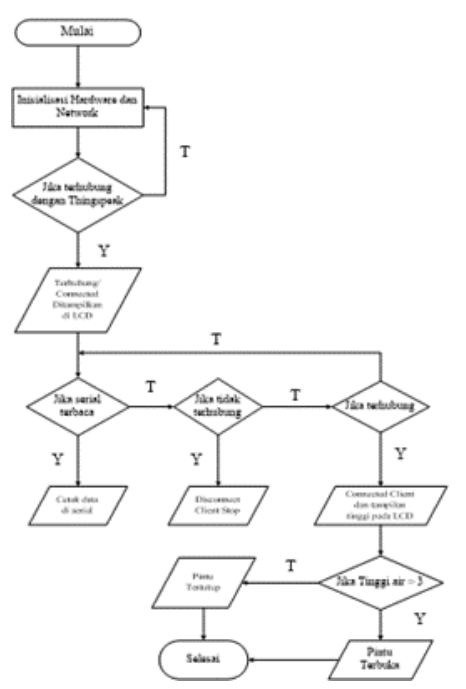

Gambar 4. Flowchart Hardware

b. Flowchart Software

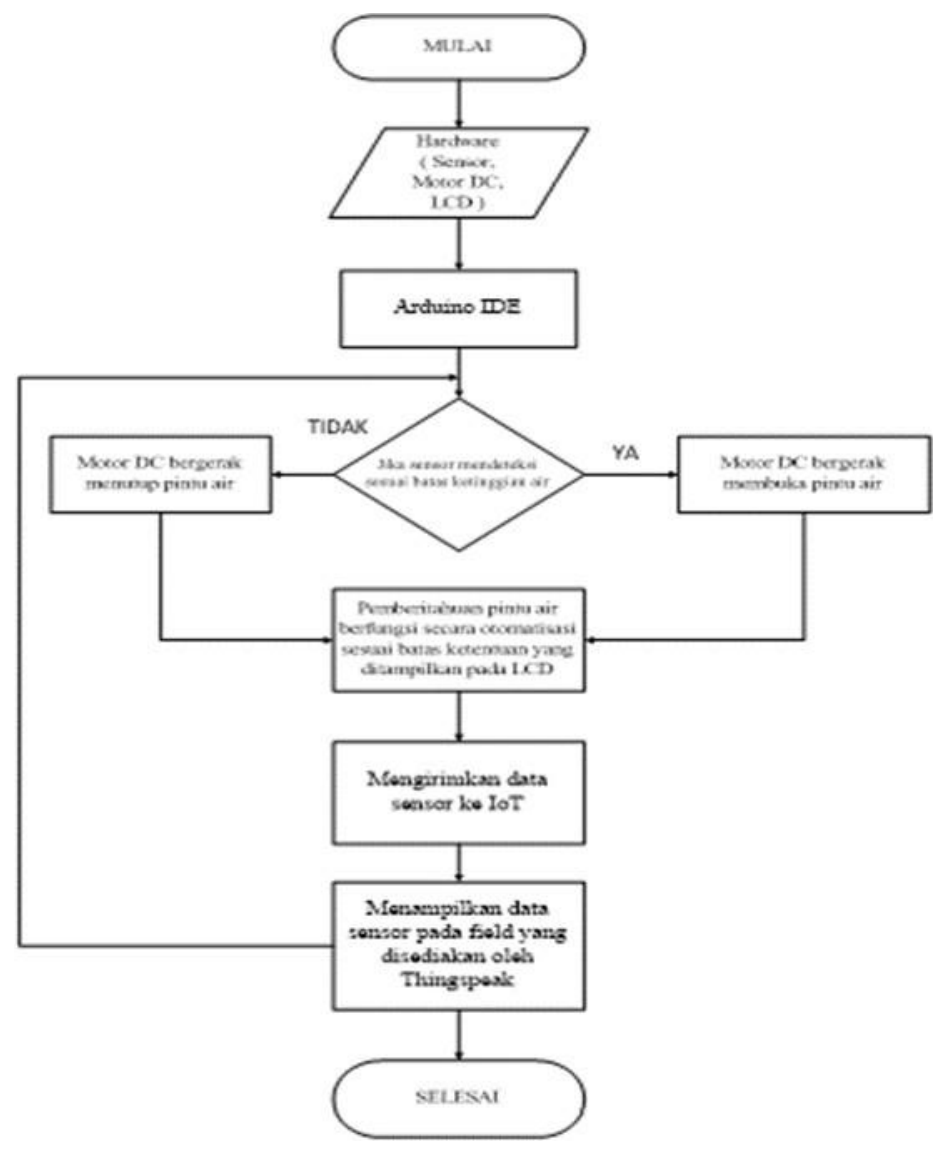

Gambar 5. Flowchart Software 


\section{HASIL DAN PEMBAHASAN}

Berdasarkan riset yang dilakukan terkait miskonsepsi Hukum II Newton, dapat dipaparkan pada tabel 1 (satu) dan 2 (dua), sebagai berikut:

Tabel 1. Data Nilai Miskonsepsi Siswa berdasarkan

Model Pembelajaran DL

\begin{tabular}{lllllc}
\hline Kelas & Model Pembelajaran & $\begin{array}{l}\text { Jumlah } \\
\text { Sampel }\end{array}$ & \multicolumn{2}{l}{ Nilai Miskonsepsi Siswa } & Rata-rata \\
\hline & & \multicolumn{5}{c}{ Tertinggi } & Terendah \\
\hline Eksperimen & Discovery Learning & 30 & 90 & 65 & 80.033 \\
\hline Kontrol & Konvensional & 30 & 80 & 50 & 67.167 \\
\hline
\end{tabular}

Berdasarkan Tabel 1, berhasil dipahami bahwasanya kegiatan pembelajaran dengan memakai model pembelajaran DL mempunyai nilai miskonsepsi Hukum II Newton yang lebih rendah dengan nilai tertinggi 90 dan nilai terendah 65 sehingga mempunyai nilai rata-rata 80.033 . Sedangkan kegiatan pembelajaran yang menggunakan model konvensional mempunyai nilai miskonsepsi Hukum II Newton dengan nilai tertinggi 80 dan nilai terendah 50 sehingga mempunyai nilai rata-rata 67.167. Tabel 1 menunjukan bahwa data miskonsepsi Hukum II Newton antara siswa grup eksperimen dan grup kontrol tidak sama.

Tabel 2. Data Nilai Miskonsepsi Siswa melalui Three Tier Test

\begin{tabular}{llllll}
\hline Kelas & Model Pembelajaran & $\begin{array}{l}\text { Jumlah } \\
\text { Sampel }\end{array}$ & Nilai Miskonsepsi Siswa & Rata-rata \\
\hline & & & Tertinggi & Terendah & \\
\hline Eksperimen & Discovery Learning & 30 & 90 & 60 & 76.3 \\
\hline Kontrol & Konvensional & 30 & 79 & 50 & 64.5 \\
\hline
\end{tabular}

Berdasarkan Tabel 2, berhasil dipahami bahwasanya kegiatan pembelajaran yang menggunakan model DL mempunyai nilai miskonsepsi Hukum II Newton dengan nilai tertinggi 80 dan nilai terendah 60 sehingga mempunyai nilai rata-rata 79.9 Sedangkan kegiatan pembelajaran yang menggunakan model konvensional mempunyai nilai miskonsepsi Hukum II Newton dengan nilai tertinggi 79 dan nilai terendah 50 sehingga mempunyai nilai rata-rata 64.5. Tabel 2 menunjukan bahwa data nilai miskonsepsi Hukum II Newton antara siswa grup eksperimen dan grup kontrol tidak sama.

Tabel 3. Hasil Uji Anova Dua Jalur

\begin{tabular}{lllll}
\hline Source & $\begin{array}{l}\text { Dependent } \\
\text { Variable }\end{array}$ & df & Sig & 35,266 \\
\hline Corrected Model & Miskonsepsi & 1 & .000 & 782,22 \\
\hline Intercept & Miskonsepsi & 1 & .01 & 3,6589 \\
\hline Kelas & Miskonsepsi & 1 & .01 & 6,254 \\
\hline
\end{tabular}

Berdasarkan tabel 3, didapat nilai taraf relevan miskonsepsi siswa 0,000 $<0,05$. Hasil ini sesuai dengan spekulasi satu, yaitu ada perbedaan miskonsepsi siswa yang menggunakan Three Tier Test 0,01 < 0,05. Model pembelajaran DL dengan model pembelajaran Konvensional. Selanjutnya didapat nilai taraf relevan $0,01<0,05$. Hasil ini menunjukkan bahwa terjadi interaksi antara model pembelajaran $D L$ menggunakan Three Tier Test terhadap miskonsepsi siswa. Dari riset ini berhasil dipahami bahwasanya model pembelajaran DL dengan Three Tier Test dapat meredam miskonsepsi siswa dan juga ditemukan adanya perbedaan miskonsepsi siswa yang menggunakan model pembelajaran DL dan siswa yang belajar memakai model pembelajaran umum. Hal ini sesuai dengan penelitian Hosnan (2014) menunjukan bahwa penggunaan model pembelajaran DL dalam pembelajaran dapat meningkatkan kemampuan penemuan dan pemahaman konsep dibandingkan model pembelajaran konvensional. 


\section{PENUTUP}

Dari hasil riset dan pemaparan diatas dapat disimpulkan bahwa (I) adanya perbandingan miskonsepsi pada siswa memakai model pembelajaran DL dan model pembelajaran konvensional, (II) adanya hubungan dari model pembelajaran DL dengan three tier test pada miskonsepsi siswa penggabungan data dan pemaparan dapat diambil kesimpulan bahwa: Ada perbedaan miskonsepsi siswa yang memakai model pembelajaran DL dengan siswa yang memakai model pembelajaran konvensional dan ditemukan adanya hubungan (interaksi) model pembelajaran DL melalui Three Tier Test terhadap miskonsepsi siswa.

Mengarah pada pembahasan dan hasil uji coba yang diperoleh, sasaran untuk penelaah ataupun penyelidik berikutnya agar model pembelajaran DL senantiasa diperluas dan dikembangkan lagi dilapangan dan dijadikan sebagai alternatif pilihan guru dalam kegiatan belajar mengajar dengan kolaborasi pengetahuan dan juga ide ataupun gagasan yang melatarbelakangi penelaah selanjutnya. Hal ini dikarenakan model pembelajaran ini dapat merangsang keaktifan peserta didik untuk mencari solusi yang diberikan dan membangkitkan semangat dan antusias belajar sehingga siswa mencapai tujuan pembelajaran yang baik dan optimal.

\section{DAFTAR PUSTAKA}

Ayu, H.D \& Jufriadi, A. 2017. Pengaruh Penerapan Strategi Open Ended Problem Bersetting Kooperatif Terhadap Kemampuan Menyelesaikan Masalah Ditinjau Dari Kreativitas Siswa. Jurnal Erudio, 7 (1): 1-6.

Arikunto, Suharsimi. 2013. Dasar-dasar Evaluasi Pendidikan. Jakarta: Bumi Aksara Depdikbud. (2015). Buku Guru Ilmu Pengetahuan Alam. Jakarta: Pembukuan Balitbang. Depdiknas. (2006). Kurikulum Tingkat Satuan Pendidikan. Jakarta: Pembukuan Balitbang.

Derosari, M. 2010. Pengaruh Pembelajaran Konteskstual Berbasis Hands On Problem Solving terhadap Kemampuan Pemecahan Masalah Siswa pada Materi Pesawat Sederhana denganRancangan Penelitian Pretest dan Posttest Design di SMP Kartika IV-9 Malang. Skripsi tidak diterbitkan: FST Unikama

Fahturrohman, Muhammad. 2015. Model-model Pembelajaran Inovatif. Jogjakarta: Ar-Ruzz Media.

Hamdani. (2011). Strategi Belajar Mengajar. Bandung: PT Bumi Aksara http://www.ekaikshanudin.net (Pembelajaran Model Discovery Learning) Kelebihan dan Kekurangan Model Discovery Learning (http://www.infosekolah87.com)

Moedjiono, Dimyati. 1993. Strategi Belajar Mengajar. Jakarta: Departemen Pendidikan dan Kebudayaan Nasional

Pranata, K.B \& Sundaygara C \& Sinmas W.F (2019). Pengaruh PBL Berbasis Class Terhadap Prestasi Ditinjau Dari Motivasi Belajar Siswa. RAINSTEK: Jurnal Terapan Sains \& Teknologi 1 (3), 14-20, 2019

Trianto, I. B. (2014). Mendesain Model Pembelajaran Inovatif, Progresif, dan Konstektual: Konsep, Landasan, dan Implementasi pada Kurikulum 2013. Jakarta: Kencana.

Yunus, H. S. (2010). Metodologi Penelitian Wilayah Kontemporer. Yogyakarta: Pustaka Pelajar

Zafira, L. (2012, Maret 14). Instrument Tes dan Nontes. Retrieved Februari 22, 2016, from http://liyanazafira.blogspot.co.id/2012/03/instrumen-tes-dan-nontes.html 